\title{
Geparalyseerd door schijnwinsten
}

\section{Bedrijfsvoering in het onbekende}

\author{
Dr. Mr. R.N.J. Kamerling
}

\section{Inleiding}

De NV Oliefabrieken Insulinde als glanzend wereldconcern, opgenomen in het selecte gezelschap van multinationals, dat was wat de leiders van de OFI in het begin van deze eeuw voor ogen stond. Grote inspirator was de vertegenwoordiger in Nederlands-Indië, B. Streefland. Onder zijn bezielende leiding werd de basis gelegd voor de onstuimige groei die het bedrijf doormaakte: omzet, produktie en winst stegen in een ongekend hoog tempo en de OFI werd van een klein regionaal copra-oliefabriekje tot de grootste industriële onderneming in Nederlands-Indië.

Op het hoogtepunt van haar ontwikkeling bezat de OFI acht modern ingerichte copra-oliefabrieken met woningen voor het personeel, een margarine-, zeep- en boteroliefabriek, opkoopstations voor copra verspreid over de gehele archipel, alsook in Singapore en Penang, eigen rollend materieel, opslagtanks te San Francisco, Londen, Amsterdam en in de grootste havenplaatsen van NederlandsIndië. Zij had twee eigen olietankers in de vaart. terwijl een derde op stapel stond. In NederlandsIndië waren ruim 5.000 werknemers in dienst. De schijnbaar onaantastbare OFI scheen een gouden toekomst tegemoet te gaan.

De gouden droom veranderde - zeker voor de aandeelhouders - in een nachtmerrie: na acht jaar van teugelloze expansie moest de OFI begin 1921 al haar fabrieken al weer sluiten met een kapitaal-

Dr. Mr. R.N.J. Kamerling RA is werkzaam bij de Belastingdienst als voorzitter van de commissie Vaktechniek van de Controle. vernietiging van maar liefst $f 57$ miljoen. Voor die tijd een enorm bedrag.

In dit artikel ga ik in op de wijze waarop de spectaculaire ontwikkeling van de NV Oliefabrieken Insulinde zich heeft (kunnen) voltrekken en door welke interne en externe factoren het concern zo snel failliet ging.

\section{De bakermat}

In 1906 nam de 29-jarige Boudewijn Streefland ontslag als opzichter bij de Rijkswaterstaat in Nederlands-Indië om te gaan bouwen aan zijn carrière als industrieel. Hij participeerde in een klein katjang-oliefabriekje. Het bedrijf floreerde en ontwikkelde zich snel. Een tweede fabriek werd in exploitatie genomen en de houten persen werden vervangen door uit Europa geïmporteerde hydraulische persapparatuur.

Bovendien was hij gaan experimenteren met andere oliehoudende zaden. De verwerking van copra, het gedroogde kiemwit van de kokosnoot, werd een doorslaand succes: de copra-olie kon tegen gunstige prijzen in Oost- en Midden Java worden verkocht.

Copra-olie werd al snel het hoofdprodukt.

Maar Streefland wilde meer. Hij was niet tevreden met het leiden van twee provinciale oliefabriekjes in een uithoek van Java. Hij was veeleer de figuur die aan het hoofd van een industrieel imperium wilde staan. Hem stonden grootse plannen voor ogen: de produktie moest daartoe drastisch worden opgevoerd en...er moest geëxporteerd worden. Kapitaalvergroting was hiertoe absolute noodzaak en moest in Nederland worden aangetrokken. Niet zonder veel moeite en overredingskracht gelukte het Streefland, einde 1912, het bedrijf te converteren in de NV Oliefa- 
brieken Insulinde. waarvan de aandelen op de Amsterdamse effectenbeurs werden geïntroduceerd.

Op 1 januari 1913 ging de maatschappij onder haar nieuwe naam van start. Amsterdam werd het hoofdkantoor. Tot directeur in Amsterdam werd benoemd Mr. J.W.D. Francken. oud-advocaat en -procureur te Soerabaja. De raad van commissarissen bestond uit drie prominente zakenlieden. Een van hen was H.G. Schadd, directeur van de Nederlandsch-Indische Handelsbank, de NIHB, de huisbankier van de OFI. Streefland zelf werd de vertegenwoordiger van de OFI in NederlandsIndië en voerde daar de scepter over de fabrieken. inclusief de in- en verkoop, die immers vrijwel geheel in Nederlands-Indië plaatsvonden. Zulk een dislokalie van leiding en bedrijf kwam in de koloniale periode wel vaker voor.

\section{Rustige groei}

$\mathrm{Al}$ spoedig bleek een duidelijk verschil van opvatting betreffende de te volgen koers. De ambitieuze Streefland stond een snelle expansiepolitiek voor ogen. Amsterdam bleef voet bij stuk houden: voor expansie was geen geld. De NIHB weigerde krediet en een aandelenemissie was gelet op de beurskoers niet mogelijk. Amsterdam was tevreden met de bestaande situatie.

Streefland zag zelf ook al vrij snel in, dat hij iets te snel van stapel liep. Want hoewel hij op export mikte, waren de gecalculeerde winsten, door de hoge emballagekosten en de aanzienlijke lekkageverliezen, slechts minimaal. Gelukkig expandeerde de thuismarkt, waar de inmiddels fors opgevoerde produktie lucratief kon worden afgezet.

\section{De Eerste Wereldoorlog}

In 1914 brak de Eerste wereldoorlog uit. Het internationale scheepvaartverkeer raakte ontwricht en daarmee tevens de wereldhandel. De copra, verreweg het belangrijkste exportprodukt van de Indonesische bevolking. kon niet meer geëxporteerd worden naar Duitsland. Van hieruit werd de snel opkomende Nederlandse en Engelse margarine-industrie van geraffineerde olie voorzien.

En juist nu was de vraag naar copra-olie groot. Door de oorlog was er van de zijde van de wapenfabrikanten een grote vraag naar een van de bijprodukten: glycerine. En het was copra-olie dat een hoog glycerinegehalte bezat. Maar ook het margarineverbruik nam snel toe. Begrijpelijk, dat de olie die de OFI te koop aanbood gretig aftrek vond.

En zo had de oorlog juist eerder een gunstige invloed op het bedrijf: alle copra-olie kon nu tegen gunstige prijzen naar Nederland worden geëxporteerd. De winstmarge bleef daarbij niet achter. omdat de inkoopprijzen van copra onder druk stonden. Sinds het uitbreken van de oorlog werd geen blik olie meer op Java verkocht. De met veel zorg opgebouwde thuismarkt werd geheel verlaten.

\section{De exportkoers}

Amsterdam kon zich volstrekt niet vinden in exportkoers die Streefland was ingeslagen. Amsterdam stelde zich op het standpunt, dat de export tot stand was gekomen door de abnormale oorlogsomstandigheden. Het abnormale bestond volgens haar hierin, dat de copraprijzen op Java terugliepen, terwijl die van copra en copra-olie in Nederland scherp opliepen. De exportmogelijkheid moest, aldus Amsterdam. nog blijken, daar deze onder meer afhankelijk was van de substitueerbaarheid van plantaardige oliën en invoerrechten. Een juiste visie. Aan deze factoren zou men later evenwel in zijn optimisme geheel voorbij gaan. De van nature optimistische Streefland ging toch zijn eigen gang.

En Amsterdam leek gelijk te krijgen. In september $1915 \mathrm{kwam}$ na de afkondiging van een invoerverbod een plotseling einde aan de export naar Nederland. Maar Streefland loste dit probleem snel op: van nu af aan richtte hij zich op de Amerikaanse markt.

Amsterdam werd optimistischer. De tomeloze Streefland maakte direct gretig gebruik van deze gunstige stemming om zijn plannen verder gestalte te geven. Vooruit. Vooruit! was zijn devies.

De Amerikaanse vraag nam sterk toe. de zeepfabrikanten gaven de voorkeur aan copra-olie boven andere oliën - glycerine! - terwijl de olie ook gretig aftrek vond bij de snel opkomende margarine-industrie.

\section{Het bulktransport}

Maar plotseling stokte de Amerikaanse vraag. De OFI kon qua prijs niet meer concurreren met de Filipijnse copra-olie. Die olie werd niet in 
blikken aangevoerd, maar met tankschepen. De OFI had haar olie alleen maar kunnen verkopen, omdat het bulkvervoer vanuit de Filipijnen tijdelijk gestagneerd was geweest.

Streefland reisde direct naar Amerika en 'veroverde' naar zijn eigen zeggen de Amerikaanse markt. In de nabije toekomst was, zo meende hij, de afzet van copra-olie in Amerika ongelimiteerd. En hij verkeerde voor wat zijn verwachtingen betreffende de snelle opkomst van de Amerikaanse margarine-industrie in goed gezelschap: ook de gevestigde Europese margarinefabrikanten geloofden in een snelle opbloei. De verwachte expansie zou evenwel pas later plaatsvinden.

Het was nu Streeflands bedoeling de copra-olie van de OFI een zeer voorname plaats te laten innemen in deze grote, op Amerika gerichte 'oliestroom'. Snel handelen was geboden, want de concurrentie zat niet stil. De produktie moest zo snel mogelijk uitgebreid worden. Daar de aanvoer van persapparatuur illusoir was, besloot Streefland de persduur te halveren. Het persrendement liep dan wel iets terug. maar de nog steeds toenemende brutowinstmarge bood voldoende speling. Bovendien werd het onderhoud tot een minimum teruggebracht. En zo was de capaciteit opnieuw verdubbeld.

De copra-olie werd van nu af aan in tankers vervoerd. De structuur van de OFI werd grondig veranderd. Dat vroeg uiteraard omvangrijke investeringen in uiterst kostbare tankwagons, tanklichters. tankschepen en opslagtanks in Nederlands-Indië en daarbuiten. Ook het verkooppatroon veranderde: de afzet in relatief kleine hoeveelheden werd vervangen door de riskantere verkoop van grote partijen. Ook de inkooppolitiek werd hier aan aangepast. En dat alles vereiste......meer vermogen.

\section{De explosieve groei}

Maar het ging de OFI voor de wind. Door de lage inkoopprijzen werd de brutowinstmarge op de olie steeds groter, evenals de winsten. Amsterdam raakte in een euforie. De voorspoedig lopende Amerikaanse verkoop beschouwde zij als een blijvende factor.

Amsterdam legde Streefland geen strobreed meer in de weg. Aan financiële middelen was geen gebrek meer. Steeds grotere aandelenemissies volgden elkaar in hoog tempo op: blijkbaar genoot het beleid van Streefland het vertrouwen van de belegger.

Maar ook de NIHB verstrekte zonder aarzeling nu op ruime schaal kredieten.

De OFI maakte een explosieve groei door. Het investeringsniveau werd versterkt door een scherpe stijging van het prijsniveau. Persinstallaties waren bijvoorbeeld tien maal zo duur geworden. Amsterdam drong aan het wat kalmer aan te doen.

Het zou niet veel helpen. Amsterdam werd bedolven onder de uitbreidingsvoorstellen. Op autorisatie wachtte Streefland feitelijk niet meer.

De zaken bleven zich voorspoedig ontwikkelen. De vraag naar copra-olie uit Amerika nam krachtig toe. De bulkverschepingen gaven, nadat de kinderziektes achter de rug waren, gunstige financiële resultaten te zien. Echter niet zo gunstig als Streefland meende. Want nu maakte hij een kapitale fout: de afschrijvingen werden niet in de kostprijs opgenomen. maar als winstverdelende post behandeld. In die tijd evenwel niet ongebruikelijk. Geen wonder dat de "exploitatie-winst' fors kon stijgen.

\section{De regeringscontracten}

Begin 1918 werd scheepvaartverkeer vanuit Nederlands-Indië gestremd. Maar op dat moment kwam de Nederlandse regering op de markt om grote hoeveelheden copra-olie op te kopen teneinde de nijpende vetvoorziening in Nederland te verbeteren. En wie anders dan de OFI zou dergelijke hoeveelheden, aldus Streefland, kunnen leveren. Op zijn aanraden werden de onderhandelingen in Nederland gevoerd. In Nederlands-Indië was het Gouvernement te goed op de hoogte van de actuele olie-prijzen. De opzet slaagde. De voorwaarden waren voor de OFI zo gunstig, dat zelfs Streefland dat niet had durven dromen. De winstmarge was enorm. De gehele produktie voor 1918 was verkocht.

Streefland was echter niet gerust op de positie van de OFI op lange termijn. Begrijpelijk: de OFI was zeer eenzijdig opgezet, er werd slechts één halffabrikaat gemaakt. Hij adviseerde om grote. meerjarige verkoopcontracten af te sluiten. De eigenlijke interesse daarvoor bij Amsterdam ontbrak. De OFI bezat nu grote vrijheid de copraolie zo duur mogelijk te verkopen; een kortzichtige visie. 


\section{Stuurloos}

Het noodlot sloeg hard toe. Begin 1919 overleed Streefland. Hij bleek zich voor de OFI onmisbaar te hebben gemaakt. want toe hij onverwacht overleed, viel er een vacuüm: de motor van het bedrijf was stilgevallen. Amsterdam moest nu plotseling zelf richting gaan geven aan de verdere ontwikkeling van de OFI.

Het bestuurlijk vacuüm dacht men met Damme, hoofd van de Dienst der Staatsspoor- en Tramwegen te Batavia, gevuld te hebben. Het was een uiterst ongelukkige keuze, die direct al aan veel kritiek bloot stond. Damme bezat namelijk weinig commerciële kennis. Hem stond een beleid 'in breeden stijl' voor ogen. Wat hij hiermee bedoelde werd al spoedig duidelijk: uitvoerig overleg en omvangrijke correspondentie. Er werd veel tijd vermorst met bijkomstigheden en hoofdzaken werden uit het oog verloren. De slagvaardigheid, de visie verdween en de OFI was van een commercieel in een log en immobiel overheidslichaam veranderd.

Zowel Amsterdam als Damme gaven zich onvoldoende rekenschap van het feit, dat aan de hoogconjunctuur een einde kon komen. De weinige voorstellen die Damme deed, kenmerkten zich alle door gebrek aan realiteitszin en overschatting van de financiële draagkracht.

Duidelijke directieven gaf Amsterdam niet. Men bleef gewoontegetrouw op Bandoeng steunen voor 'aanwijzingen". Het resultaat, was dat er eigenlijk geen sprake meer was van leiding en coördinatie.

Toen Damme medio mei 1919 zijn werkzaamheden te Bandoeng aanving, zette de verwachtte na-oorlogse hausse pas goed in. De Indische export expandeerde enorm. Speculatie in copra en suiker vierde hoogtij. De Indische economie vertoonde het beeld van een overspannen inflatie, waarin enorme (boek-)winsten werden behaald. Er heerste onbegrensd optimisme.

De OFI leek het voor de wind te gaan. De olieprijzen stegen tot ongekende hoogte. Maar ook de copraprijzen vlogen omhoog en relatief veel sterker: de winstmarge schrompelde sterk in. ja verdween zelfs geheel. Daar de OFI haar grote copravoorraden evenwel volgens nominalistisch principe - gemiddelde inkoopprijzen - bleef waarderen, had men niet in de gaten, dat de produktie op basis van actuele prijzen niet rendabel meer was.
Alleen voorradwinsten hielden de OFI overeind. Op papier verkreeg men bij elke verkooptransactie een fraaie winst. Zo bracht men zichzelf in euforie, in een roes, waarin men de economische draagkracht van het bedrijf sterk overschatte.

Geparalyseerd door de schijnwinsten koerste het bedrijf zijn ondergang tegemoet.

Bevangen door het 'ongezonde optimisme' gaf Damme de instructie kolossale hoeveelheden op te kopen tegen...topprijzen. Alle copra, hoe jong, schimmelachtig of rot ook werd uit concurrentieoverwegingen geaccepteerd. In feite was het de OFI zelf die het prijsniveau opstuwde.

De opkoop van die immense hoeveelheden werd ingegeven door de angst van Damme, dat er later geen copra meer te krijgen zou zijn tegen gunstige prijzen. Hij bleef blind vertrouwen op een nieuwe hausse die de copraprijzen tot ongekende hoogte zouden opdrijven. Hij wilde hoe dan ook enorme voorraden aanhouden.

Toen de prijzen van copra op hun hoogtepunt waren, de olieprijzen afbrokkelden en van een winstmarge, bij stagnerende verkopen, reeds lang geen sprake meer was, bleef Damme - gedreven doorkopen om zo de voorraad - nota bene - tegen topprijzen in stand te houden.

In deze periode waren er geen goede voorraadoverzichten meer en was de administratieve organisatie wanordelijk. Deze had geen gelijke tred gehouden met de sterke expansie van het bedrijf.

Onder het bewind van Damme gleed de OFI langzaam af naar een administratieve chaos. Ook had men geen inzicht meer in de opbouw van de kostprijs. Zo meende Damme dat hij door het verhogen van de produktie de kostprijs aanzienlijk zou dalen. Maar in werkelijkheid maakten de produktiekosten door de hoge copraprijzen. nog maar een klein gedeelte uit van de kostprijs.

Maar eigenlijk kan niet alleen Damme gebrek aan inzicht verweten worden. Ook Amsterdam trad niet slagvaardig op. Men liep achter de feiten aan. De steeds hogere produktie kon niet meer afgezet worden. Kennis van de verkoopmarkt ontbrak. Amsterdam miskende de positie van copra-olie op de internationale markt. De zeep- en margarine-industrie konden namelijk zowel technisch als commercieel overschakelen van de ene op de andere oliehoudende grondstof. In vredestijd moest de (copra-)olie in de pas lopen met de prijs van andere oliën. Maar Amsterdam 
wilde het onderste uit de kan. Zo werden veel verkoopkansen onbenut gelaten. De olie zou later, zo meende men. wel gesleten kunnen worden tegen gunstiger voorwaarden.

Gevolg van dit dodelijke verkoopbeleid, in combinatie met het optimistische inkoopbeleid. was. dat enorme economische voorraden ontstonden, die als een zwaard van Damocles boven de OFI zweefden. Economische voorraden die gigantische kapitalen opslorpten. Vermogen, dat door de NIHB maar al te gretig werd verstrekt. Schadd, directeur van de NIHB, zou als commissaris van de OFI toch hebben moeten weten, hoe slecht de werkelijke positie van het concern was. Zonder enige bedenking pompte hij in enkele maanden tientallen miljoenen guldens in een bodemloze put. Voor hij en de andere commissarissen goed en wel beseften wat er gebeurde. was er geen weg terug meer.

\section{Het debầcle}

Ultimo 1920 zette een korte maar felle depressie in. Op de sterke inflatie volgde een bijna even sterke deflatie. De westerse sector in NederlandsIndië. die met de wereldeconomie verweven was. onderging de internationale economische neergang ten volle. De noteringen van copra en copra-olie tuimelden binnen twee weken met $50 \%$ respectievelijk met $40 \%$. En de prijzen bleven verder afbrokkelen.

Voor de internationale olie-, margarine- en vetindustrie was het een dramatische ontwikkeling. De Engelse en Nederlandse margarinefabrikanten hadden namelijk tijdens en kort na de Eerste Wereldoorlog hun bedrijven op koortsachtige wijze uitgebreid: de firma's Jurgens en Van den Bergh waren uitgegroeid tot verticale combinaties van indrukwekkend formaat. De Engelse zeeptitaan Lever had de zaken zelfs zo voortvarend aangepakt. dat Wilson spreekt van een razernij in de zakenwereld". die leidde 'tot het toppunt van dwaasheid". Alle concerns hadden zeer aanzienlijke sommen gelds in grondstoffen geïnvesteerd. Op de economische voorraden werden gigantische verliezen geleden. De grote maatschappijen wankelden. Voor de reeds gedesintegreerde huishouding van de $\mathrm{OFI}$ die haar grote economische voorraden grotendeels met vreemd vermogen had gefinancierd, was het de nekslag. De OFI bleek "een reus op lemen voeten'. Op 7 april 1921 zette de oliefabriek te Makassar als laatste haar persbatterijen stil. Een van de grootste debâcles op industrieel gebied in Nederlands-Indië was hiermee een feit.

\section{De OFI in cijfers}

De primaire oorzaak van het échec valn de OFI moeten wij voornamelijk zoeken bij de interne. bedrijfseconomische factoren.

De leiding van de OFI, zowel die te Bandoeng als die te Amsterdam, had een volstrekt verkeerd beeld had van de interne structuur van het bedrijf en de plaats van de OFI op de internationale markt.

Op bedrijfseconomische vraagstukken werd verkeerd gereageerd. De ernstigste fout was de wijze. waarop de OFI de hoge inflatie in haar bedrijfsbeleid verdisconteerde. De manier waarop met de sterke inflatoire tendensen rekening werd gehouden, werkte door op bijvoorbeeld de inkoop. de verkoop, het financiële beleid en de uitkeringspolitiek.

Van belang is te weten welke waarderingsgrondslagen bij de leiding van de OFI bekend verondersteld mochten worden om de invloed van de inflatie bij de winstbepaling te neutraliseren.

Wij zullen ons hierbij beperken tot de waardering van de grondstofvoorraden, omdat de grondstof (de copra) verreweg de belangrijkste kostprijscomponent was en juist de waardering van deze voorraad geleid heeft tot misslagen in de bedrijfspolitiek, die de OFI heeft gevoerd.

\section{Historisch perspectief}

De invloed van de inflatie op de kostprijscalculatie en winstbepaling is pas sinds het einde van de jaren twintig van deze eeuw object van onderzoek in de bedrijfseconomische wetenschap. Dit mag geen verwondering wekken, wanneer men bedenkt, dat tot 1914 het algemeen prijsniveau een betrekkelijk stabiel karakter vertoonde. Sedert het begin van de Eerste Wereldoorlog is het prijsniveau evenwel, met name in Duitsland, aan grote schommelingen onderhevig geweest. Door de onrust op het prijzenfront zijn op het gebied van de waarderingsgrondslagen nieuwe waarderingsstelsels geïntroduceerd; de nominalistische methode bleek voor de winstbepaling bij scherpe prijsstijging niet langer te voldoen. ja, leidde zelfs tot onjuiste beslissingen op alle gebieden van de bedrijfsvoering. Omstreeks 1913, toen de OFI 
werd opgericht. was het echter nog algemeen gebruik de voorraden volgens nominalistische methode te waarderen. In deze periode van relatieve prijsstabiliteit was de aandacht voor andere waarderingsgrondslagen gering.

De sterke prijsstijgingen in en na de Eerste Wereldoorlog brachten evenwel heel duidelijk de bezwaren van dit systeem naar voren. Met behulp van de op nominalistische wijze berekende kostprijs kon de OFI bij voortdurende inflatie bijzonder moeilijk een indruk krijgen of haar verkoopprijs nog enige transactiewinst liet. Er bestond een 'time-lag" tussen het moment van de prijsstijging op de inkoopmarkt en het moment van de kostprijsstijging. Deze 'time-lag' wordt bepaald door de (grote) omvang van de voorraden die op het moment van prijsstijging aanwezig waren en de snelheid waarmee deze voorraden in het produktieproces opgingen. Dit leidde niet alleen tot een sterk vertraagde aanpassing van de verkoopprijs, maar oefende ook grote invloed uit op de winstbepaling, die doorwerkte in de financiële politiek en de uitkeringspolitiek.

Welke substantialische theorieën waren nu. afgezien uiteraard van praktisch inzicht, zover ontwikkeld, dat zij door de OFI zouden kunnen zijn toegepast? De enige theorie die hiervoor in Nederland in aanmerking komt was het ijzeren voorraadstelsel.

Reeds begin 1917 werden door Volmer de grondslagen van dit stelsel gelegd. Het stelsel valt als een partiële toepassing van het substantialisme te kwalificeren.

\section{De schijnwinsten}

Eigenlijk is de OFI te gronde gegaan aan haar winsten. Dit lijkt op het eerste gezicht tegenstrijdig. De leiding had namelijk een volstrekt onjuist beeld van het begrip 'winst'. Zij verstond daaronder het verschil tussen verkoopprijs en kostprijs.

Dat is op zich niet incorrect. maar het begrip kostprijs werd nu juist verkeerd gehanteerd. Zo verzuimde men bijvoorbeeld om in de kostprijs de grondstofcomponent anders te gaan waarderen, toen het moment dat vereiste. Door in een tijd van hyperinflatie (1919) vast te houden aan de nominalistische waarderingsgrondslag - te weten de gemiddelde inkoopprijs - kwam de marktprijs pas met grote vertraging in de kostprijs tot uitdrukking. Hierdoor in 1919 grote (voorraad-) winsten behaald. Amsterdam onderkende dat op sommige momenten ook wel, maar omdat ander 'te weinig winst zou vrijvallen", hield men toch vast aan het nominalistisch systeem.

Men verzuimde verder de afschrijvingen en andere kosten in de kostprijs op te nemen. Hoewel Amsterdam het theoretisch juist vond de afschrijvingen in de kostprijs op te nemen, wees ze het voorstel toch van de hand. 'Theorie en praktijk zijn toch immers dikwijls met elkaar in conflict'. De afschrijvingen werden zelfs bewust laag gehouden teneinde voldoende winst te kunnen laten zien en....uit te keren.

Zodoende verkreeg men bij elke verkooptransactie op papier - en dus niet in realiteit - een fraaie winst. Schijnbaar rechtvaardigde dit een verder expanderen van het bedrijf.

Daarvoor was kapitaal nodig. dat gemakkelijk aangetrokken kon worden van aandeelhouders die aangelokt werden door de superdividenden. Het onaangename was echter. dat de winst geheel opging aan dividenden. Mede daardoor ontstond een kapitaaltekort, dat slechts aangezuiverd kon worden door opnieuw een beroep op de aandeelhouder te doen. Zo kwam men in een spiraal terecht waar men niet meer uit kon komen. De greep op het vermogen had men verloren.

\section{Exposure}

In de jaarrekeningen bracht de OFI weinig essentiële fïnanciële criteria naar buiten. Doch ook intern werden deze echte relevante criteria. zoals de rentabiliteit veronachtzaamd.

Bovendien is de terminologie die de OFI in haar gepubliceerde jaarrekeningen bezigde. misleidend; wat extern (exploitatie-)winst werd genoemd, verdiende veeleer de kwalificatie 'exploitatiesaldo'.

Op basis van de archiefstukken hebben wij de resultaten opnieuw samengesteld. 'Schoonheidsen winstgebreken' zijn hersteld. Uit de cijferanalyse blijkt dat in 1919 een voorraadwinst is behaald van ruim $f 6$ miljoen. Dit bedrag gesteld tegenover de exploitatiewinst, toont aan, dat zonder deze voorraadwinst de OFI per saldo een groot verlies zou hebben geleden. In feite was de OFI sinds midden 1919 niet meer rendabel.

Niettemin bracht een aandelenemissie op 1 oktober van dat jaar nog $f 15$ miljoen op; emissiekoers $200 \%$. In de emissieprospectus stond volkomen ten onrechte vermeld, dat 'de sedert enkele maanden snel opgeloopen olieprijzen 
gelijken tred (hielden) met de prijsstijging der grondstoffen.' Damme gaf enkele maanden daarvoor al aan, dat produktie op basis van de huidige copraprijzen niet rendabel meer was. Uitdrukkelijk vermeldde hij dat hij nog geen rekening had gehouden met de rente- en afschrijvingscomponent. Met deze wetenschap deed men niets. Men bleef blind vertrouwen in een nieuwe hausse.

In 1920 wordt de rekening gepresenteerd. De "kostprijs" was nu zo hoog geworden, dat de OFI geen winstmarge overbleef. Typerend voor de situatie was dat Amsterdam nog informeerde of er niet sprake was van een 'tik- of calculatiefout'.

Over het boekjaar 1920 becijferde de OFI een verlies van een kleine $f 20$ miljoen. Amsterdam besloot daarop de voorraladresultaten direct ten laste van de agioreserves af te boeken. De verliesen winstrekening geeft zodoende een verlies van $f 3,4$ miljoen te zien. Het eigen vermogen was in tegenstelling tot de visie van Amsterdam reeds danig 'aangetast'.

Wat Amsterdam echter vergat was dat de copra-olie die in Nederlands-Indië was verscheept tegen (hoge) verkoopprijzen was 'uitgeboekt". En die olie was nog niet verkocht.

Daar kwam bij dat door de scherpe deftatie de vaste activa voor een veel te hoge waarde op de balans stonden. Enorme afschrijvingen - om en nabij de $f 20$ miljoen - warren noodzakelijk om de boekwaarde meer in overeenstemming met de werkelijkheid te brengen. Bovendien hadden de vaste activa niet meer op 'going concern' waarde gebaseerd mogen worden. maar - in ieder geval gedeeltelijk op liquidatiewaarde. Alle fabrieken stonden immers stil. Bovendien had men de reeds een voorzienig moeten treffen voor de 'kosten valn stillegging'. De werkelijke omvang van de verliezen die ultimo 1920 waren geleden beliepen dan ook reeds veel meer dan $f 40$ miljoen; een bedrag van geheel andere orde dan het verlies van $f 3,4$ miljoen gulden dat de aandeelhouders werd voorgehouden.

Door de wijze waarop de resultaten nu aan de aandeelhouders werden gepresenteerd, werd de toestand veel te rooskleurig afgeschilderd. De accountant kon dan ook eerst na veel moeite worden overgehaald de jaarstukken zonder voorbehoud te tekenen.

Veel deed het er echter niet meer toe. 